American J. of Engineering and Applied Sciences 3 (1): 152-158, 2010

ISSN 1941-7020

(C) 2010 Science Publications

\title{
Energetic Performances Study of an Integrated Collector Storage Solar Water Heater
}

\author{
O. Helal, B. Chaouachi, S. Gabsi and C. Bouden \\ Unit of Research: Environment Catalyzes and Process Analysis, \\ National School of Engineers of Gabes, Avenue Omar Ibn Khettab, 6029 Gabes, Tunisia
}

\begin{abstract}
Problem statement: Although that the interest attributed to the solar energy remains relatively limited, we attend today to the conception of several installations using the sun as energy source among which we quote the solar water heater. Approach: A study of energetic performances was taken on an integrated collector/storage solar water heater made in the National School of Engineers of Gabes. This water heater is equipped with a concentration system containing a reflector composed of three parabolic branches favorating a better absorption of solar radiance. Results: The comparison between this system and two other systems of solar water heater, composed of a storage ball with asymmetrical CPC and symmetrical CPC, showed important energetic performances despite the simplicity and the little cost of the collector. Conclusion: Several improvements are necessary to increase the direct flow whilst decrease the thermal losses and therefore make the system simpler to be installed on the building roof.
\end{abstract}

Key words: Solar energy, solar water heater, integrated collector/storage, energetic performances

\section{INTRODUCTION}

Solar energy is the biggest hope for an inexhaustible energetic source notably for the countries having a strong flow of sunshine such as Tunisia that receives about $3000 \mathrm{~h}$ year ${ }^{-1}$ of it with a global mean daily radiation of $5 \mathrm{KWh} \mathrm{m}{ }^{-2}$ (Teyeb et al., 2006; Tripanagnostopoulos et al., 2002).

The production of hot water using solar water heater represents one of the most important applications of the solar energy (Tripanagnostopoulos et al., 2002). The quick evolution of modern technologies that use this energy drove to the development of several types of solar water heater systems. These systems are classified in two classes: Solar water heater with separated elements and integrated collector storage solar water heaters (Tripanagnostopoulos et al., 2002; Smyth et al., 2004).

Among domestic hot water solar systems that can satisfactorily cover the need of about 100-200 1 day $^{-1}$ of hot water in the low temperature range of $40-70^{\circ} \mathrm{C}$, we find the Integrated Collector Storage (ICS) systems (Tripanagnostopoulos et al., 2002). These systems consist of one device with dual operation, to collect solar radiation and to preserve the heat of the water storage tank during the night (Souliotis and Tripanagnostopoulos, 2004). ICS systems are less applied solar water heaters because of their higher storage thermal losses during the night (Souliotis and Tripanagnostopoulos, 2004; Smyth et al., 2001), although they are cheaper and more aesthetically attractive than the thermosiphonic systems (Souliotis and Tripanagnostopoulos, 2004; Adsten et al., 2005).

Several studies are referred to the design and thermal performances of ICS systems, including suggested improvements which aim to achieve low cost systems with considerable performance by maximizing solar radiation collection whilst minimizing thermal losses (Tripanagnostopoulos and Yianoulis, 1992; Tripanagnostopoulos et al., 2000; Schmidt and Goetzberger, 1990).

Thermal performances of ISC systems during both day and night depend on the designs principles and the used materials, as well as the weather conditions.

We are interested here to study the energetic performances of an integrated collector storage solar water heater with Compound Parabolic Concentrating (CPC) reflectors, which is made in the Research Unit: Environment, Catalyzes and Process Analysis of the National School of Engineers of Gabes. This system is carried out with the intention to improve its energetic efficiency and to widen its useful domain. The experimental results are at first analyzed then compared with those obtained using two different solar water heater with CPC.

Corresponding Author: O. Helal, Unit of Research: Environment Catalyzes and Process Analysis,

National School of Engineers of Gabes, Avenue Omar OIbn Khettab, 6029 Gabes, Tunisia 


\section{MATERIALS AND METHODS}

Experimental study and measurement techniques: We study an integrated collector storage solar water heater based on single cylindrical storage tank on stainless steel as more suitable and durable material placed inside a trunk thermally insulated (Chaouachi and Gabsi, 2006; Tripanagnostopoulos and Souliotis, 2004). This insulation is covered by a reflector composed of three parabolic branches. We placed an opaque and selective glazing as a system transparent cover which surface is equal to $1.92 \mathrm{~m}^{2}$ (Smyth et al., 1999).

The system cylindrical storage tank is placed in the CPC reflector trough by means of a support letting the free rotation of the latter around the axis of the absorber and a variable inclination of all the system (Chaouachi and Gabsi, 2006). The collector is brought up on a fixing support open to sky allowing the free circulation of the air around the frontal and back parts of the latter. The support inferior edge must be situated at last $0.5 \mathrm{~m}$ above the ground surface. The inclined angle was set up to $36^{\circ} \mathrm{C}$ (Fig. 1).

The surface of concentration of the solar rays $\mathrm{A}_{\mathrm{ab}}=$ $1.4 \mathrm{~m}^{2}$ and the aperture surface is $\mathrm{A}_{\mathrm{a}}=1.6 \mathrm{~m}^{2}$ that gives a concentration factor $\mathrm{C}=1.2$. The cylindrical storage tank has a diameter of $\mathrm{D}_{\mathrm{T}}=0.27 \mathrm{~m}$, a length of $\mathrm{L}_{\mathrm{T}}=$ $1.665 \mathrm{~m}$ and therefore the total stored water volume is $\mathrm{V}_{\mathrm{T}}=951$.

Based on the experience of the testing procedure, we tested the system by measuring the variation of the water temperature in the storage tank regarding the ambient temperature, the incoming solar radiation and the wind speed. For this purpose, we used data logger Testo 950 which allows to measure the direct and diffuse solar flow as well as the speed of the wind, the temperature and the humidity (Chaouachi and Gabsi, 2006).

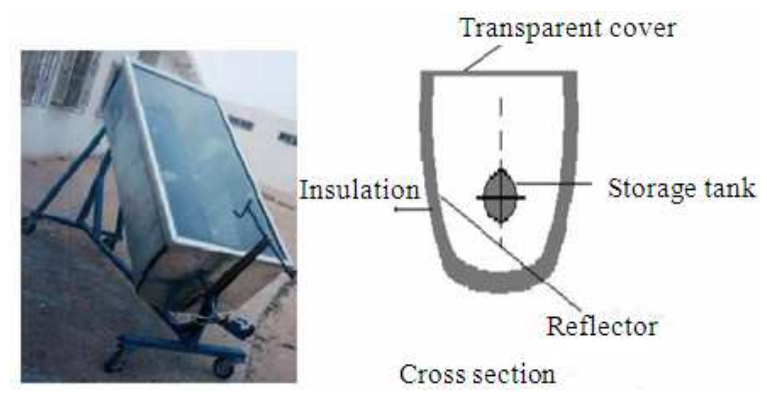

Fig. 1: Front view of the integrated collector storage solar water heater
It requires the measurement of the temperature profile of the water in the system storage tank from bottom to top by using thermocouples (type $\mathrm{K}$ ) inside it. Three sensors which must be placed (fixed) at a maximum distance of $200 \mathrm{~mm}$ from the open part of the system were used in the storage tank (Fig. 2). The energetic performances are judged according to three different orientations: Southeast, South and Southwest.

The target is to determine the daily production of hot water given by our system; we set up at first the water drain temperature. Then, we carried out every hour a water drain from the storage top level at the wished temperature until the first fall of this last one. We studied the production schedule of the system for several temperatures of water drain in order to know the suitable moment for the exploitation of hot water. This method describes well the real conditions of domestic hot water use (Chaouachi and Gabsi, 2006).

The mean daily efficiency $\eta_{d}$ of the system is determined by means of the Input-Output method which consists on leaving the system operates from the morning $(6: 00 \mathrm{~h})$ to the afternoon $(18: 00 \mathrm{~h})$ and measure the incident solar flow (Chaouachi and Gabsi, 2006; Souliotis et al., 2009). The water temperature is measured per hour and consequently the thermal stocked energy is deducted through a constant water drain fixed to $1 \mathrm{~L} \mathrm{~h}^{-1}$.

The calculation of the mean daily efficiency $\eta_{d}$ of the system is based on the equation given by (Chaouachi and Gabsi, 2006):

$\eta_{\mathrm{d}}=\frac{\mathrm{Q}_{\mathrm{w}}}{\mathrm{CQ}_{\mathrm{R}}}$

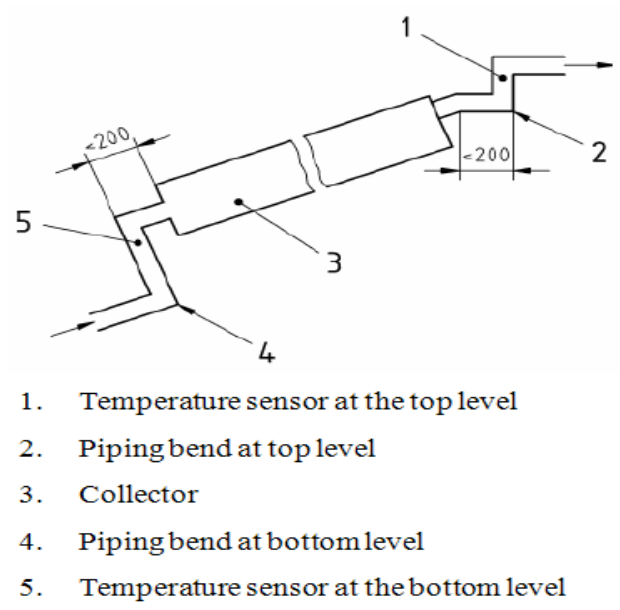

Fig. 2: Available sensors measure 
The water mass $M_{w}(K g)$, the specific heat $\mathrm{C}_{\mathrm{p}, \mathrm{w}}\left(\mathrm{Jkg}^{-1} \mathrm{~K}^{-1}\right)$ and the initial $\mathrm{T}_{\mathrm{i}, \mathrm{m}}(\mathrm{C})$ and final $\mathrm{T}_{\mathrm{f}, \mathrm{m}}(\mathrm{C})$ system mean water temperatures determine the heat quantity $\mathrm{Q}_{\mathrm{w}}(\mathrm{J})$ given by the equation:

$\mathrm{Q}_{\mathrm{w}}=\mathrm{M}_{\mathrm{w}} \mathrm{C}_{\mathrm{p}, \mathrm{w}}\left(\mathrm{T}_{\mathrm{f}, \mathrm{m}}-\mathrm{T}_{\mathrm{i}, \mathrm{m}}\right)$

The total solar radiation intercepted by the aperture surface $A_{c}\left(m^{2}\right)$ of the system during the interval $\Delta t(s)$ from the start point $t_{i}$ in the morning to the final point $t_{f}$ in the afternoon is given by the parameter $Q_{R}(J)$, which is determined by the integration of the solar radiation intensity $\mathrm{G}(\mathrm{t})$ :

Where:

$Q_{R}=A_{a} \int_{t_{i}}^{t_{f}} G(t) d t$

The mean solar radiation on the aperture plane is given by the equation (Chaouachi and Gabsi, 2006):

$G_{m}=\frac{\left(\int_{t_{i}}^{t_{f}} G(t) d t\right)}{\Delta t}$

To determine the thermal losses coefficient of the system, we leave this one operates during the day with out water drain, we measure the water temperature at storage bottom $\mathrm{T}_{\mathrm{i}, \mathrm{b}}$ and top $\mathrm{T}_{\mathrm{i}, \mathrm{t}}$ at 18:00 h. The average water temperature $T_{i, m}$ at the starting point in the afternoon is calculated according to the following formula (Chaouachi and Gabsi, 2006):

$\mathrm{T}_{\mathrm{i}, \mathrm{m}}=\frac{\mathrm{T}_{\mathrm{i}, \mathrm{b}}+\mathrm{T}_{\mathrm{i}, \mathrm{t}}}{2}$

Then we leave the system to operate during the night without water drain, we calculate the final mean water temperature the next morning $\mathrm{T}_{\mathrm{f}, \mathrm{m}}$ at $6: 00 \mathrm{~h}$ by the same formula (6). The mean ambient temperature $\mathrm{T}_{\mathrm{a}, \mathrm{m}}$ in the time interval $\Delta \mathrm{t}$ during the system operation at night is determined using a data logger. The mean water temperature is given by:

$\mathrm{T}_{\mathrm{m}}=\frac{\mathrm{T}_{\mathrm{i}, \mathrm{m}}+\mathrm{T}_{\mathrm{f}, \mathrm{m}}}{2}$

The thermal losses coefficient $U_{s}$ is extracted by the operation during the night, as system thermal behavior from afternoon until next morning. It is calculated by the relation (Chaouachi and Gabsi, 2006):

$\mathrm{U}_{\mathrm{s}}=\left(\frac{\rho \mathrm{C}_{\mathrm{p}, \mathrm{w}} \mathrm{V}_{\mathrm{T}}}{\mathrm{T}_{\mathrm{f}, \mathrm{m}}-\mathrm{T}_{\mathrm{i}, \mathrm{m}}}\right) \operatorname{Ln}\left[\frac{\mathrm{T}_{\mathrm{i}, \mathrm{m}}-\mathrm{T}_{\mathrm{a}, \mathrm{m}}}{\mathrm{T}_{\mathrm{f}, \mathrm{m}}-\mathrm{T}_{\mathrm{a}, \mathrm{m}}}\right]$

\section{RESULTS AND DISCUSSION}

Experimental results: The constructed ICS prototype was tested outdoors to determine its main daily efficiency $\eta_{d}$ and the coefficient of thermal losses $U_{s}$ during the night. The experiments were performed during May for three different orientations (Southeast, South, Southwest) and under similar weather conditions (clear sky, weak speed of wind).

Water temperature variation profiles: The variations of the solar flow $G_{m}$ and the mean water temperature $\mathrm{T}_{\mathrm{m}}$ at the level of the storage tank are presented among three orientations which are Southeast, South and Southwest.

Southeastern orientation: Figure 3 shows that the progressive increase of the solar flow in the morning enhances the increase of the mean water temperature which attains the threshold of about $60^{\circ} \mathrm{C}$ at $14: 30 \mathrm{~h}$. The peaks of the solar flow and the mean water temperature profiles are reached at the same time which is explained by the fact that the collector is facing sun in the morning and then it receives the heat when the water is cold.

Then, the decrease of the solar flow since 14:30 h causes the immediately decrease of the mean water temperature which reaches $50^{\circ} \mathrm{C}$ at $18 \mathrm{~h}$.

Southern orientation: In Fig. 4, we notice that the peaks of the solar flow and the mean water temperature profiles are shifted of about $3 \mathrm{~h}$. In fact, the solar flow attains its maximum value at $13 \mathrm{~h}$ while the mean water temperature profile is at its maximum value of $57.5^{\circ} \mathrm{C}$ at $16 \mathrm{~h}$. This gap is due to the collector orientation which is facing sun only since $11 \mathrm{~h}$.

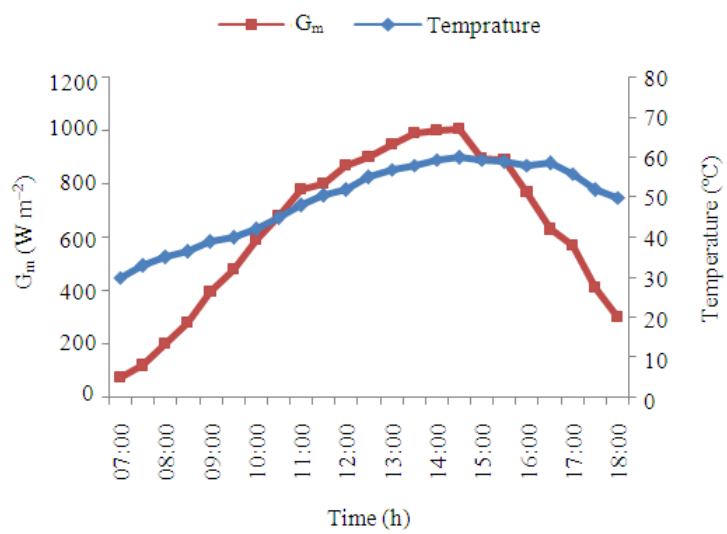

Fig. 3: Variation of the mean water temperature of the storage tank for a sequence of $11 \mathrm{~h}$ operations for the Southeastern orientation 
Am. J. Engg. \& Applied Sci., 3 (1): 152-158, 2010

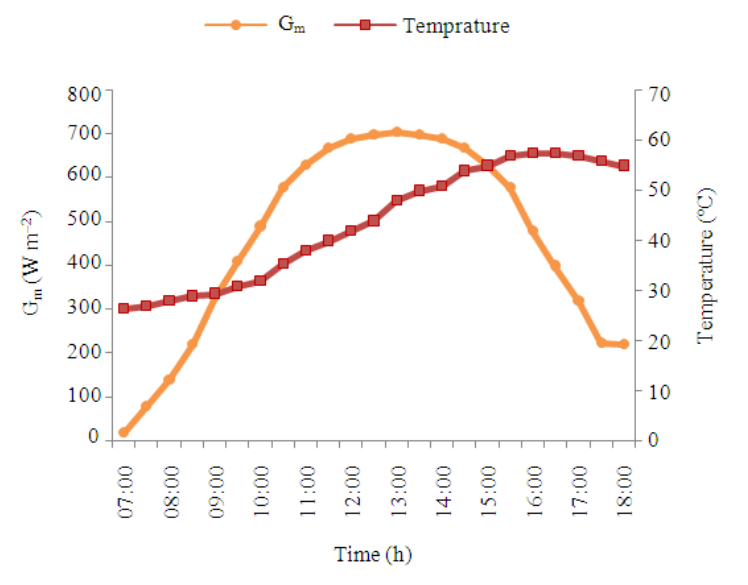

Fig. 4: Variation of the mean water temperature of the storage tank for a sequence of $11 \mathrm{~h}$ operations for the Southern orientation

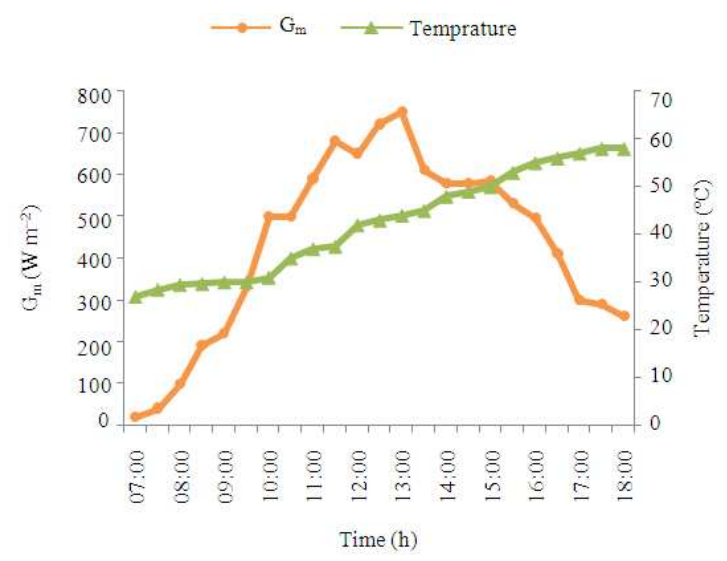

Fig. 5: Variation of the mean water temperature of the storage tank for a sequence of $11 \mathrm{~h}$ operations for the Southwestern orientation

Southwestern orientation: Figure 5 shows that the gap between the peaks of the solar flow and the mean water temperature profiles is larger than that seen in the Southern orientation $(5 \mathrm{~h})$. It is explained by the fact that the collector is facing sun only since $13 \mathrm{~h}$. The mean water temperature attains its maximum value of about $58^{\circ} \mathrm{C}$ at $18 \mathrm{~h}$.

In Fig. 6, the variation of the mean water temperature profile among the three studied orientations is presented. It shows that the southeastern orientation is the most suitable one to use sanitary hot water in the morning with a mean water temperature attaining the threshold of about $60^{\circ} \mathrm{C}$ at $14: 30 \mathrm{~h}$. The southern orientation performers better when the user needs hot water between the afternoon and the evening with a mean water temperature of about $57.7^{\circ} \mathrm{C}$ towards $16: 00 \mathrm{~h}$.

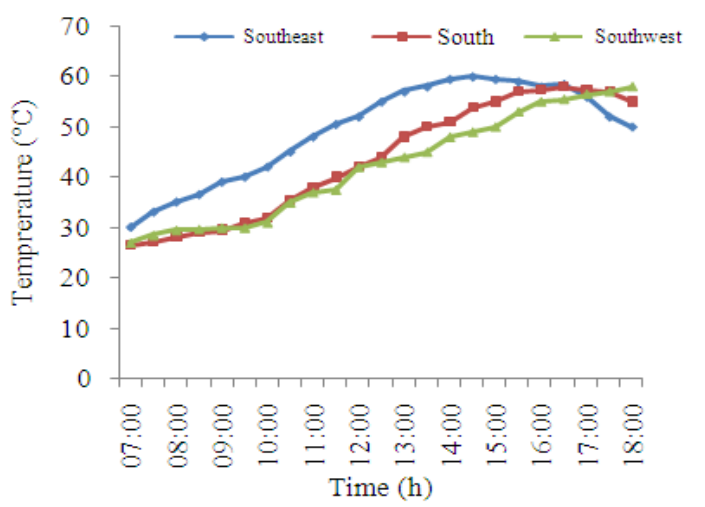

Fig. 6: Variation of the mean water temperature of the storage tank for a sequence of $11 \mathrm{~h}$ operations for three orientations: Southwest, South and Southeast

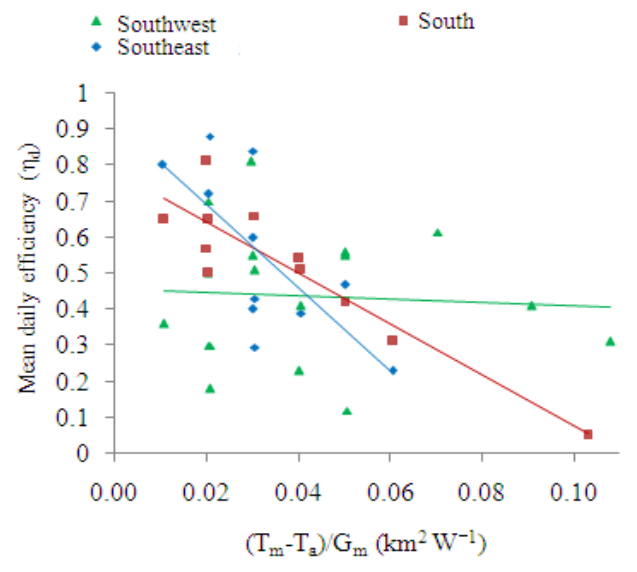

Fig. 7: Mean daily efficiency experimental results of the prototype

In order to obtain hot water at night, the Southwestern orientation is the most adequate offering a mean water temperature of about $58^{\circ} \mathrm{C}$ at $18: 00 \mathrm{~h}$.

Mean daily efficiency: In Fig. 7, we present the experimental results of the tested system regarding its mean daily efficiency $\eta_{d}$, as a linear function of the ratio $\left(\frac{\Delta T}{G_{m}}\right)$. The Southeastern orientation shows that for weak value of the ratio, the mean daily efficiency attains maximum values (about $80 \%$ ) then it decreases to attain $20 \%$ for a ratio of about 0,065 . This can be explained by the fact that more the difference between the mean water temperature of the storage tank and the mean ambient temperature is weak more the convecting thermal losses become weaker and therefore more the efficiency grows up. 
The Southern orientation allows smaller slope the mean daily efficiency's linear fitting than that found in the Southeastern orientation. The ratio reaches a high value of about 0.1 when the mean daily efficiency value is equal to 0.09 .

The Southwestern orientation shows that the maximum value of the mean daily efficiency in the morning is about $60 \%$, then it decreases attaining $40 \%$ for a ratio of about 0.1 . We notice that the decrease of the mean daily efficiency is slower than that seen in the Southeastern and Southern orientations.

Thermal losses during the night: In Fig. 8, we present the results from the tests performed during the night with the aim to determine the heat loss coefficient $U_{s}$. The results show that the loss coefficient increases with the difference between the mean water temperature of the storage tank measured in the afternoon and the mean ambient temperature $\left(\mathrm{T}_{\mathrm{m}}-\mathrm{T}_{\mathrm{a}, \mathrm{m}}\right)$. In fact, for a gap of the latter difference of $24^{\circ} \mathrm{C}, \mathrm{U}_{\mathrm{s}}$ is maximum and it values about $9,33 \mathrm{~W} \mathrm{~K}^{-1} \mathrm{~m}^{-2}$. While, for a weak value of $\left(\mathrm{T}_{\mathrm{m}}-\mathrm{T}_{\mathrm{a}, \mathrm{m}}\right), \mathrm{U}_{\mathrm{s}}$ is at the value of $8 \mathrm{~W} \mathrm{~K}^{-1} \mathrm{~m}^{-2}$. The thermal losses grow up when the difference of temperature increases since the heat convecting flow coming from the storage tank appears as soon as the water temperature inside it becomes superior to the ambient temperature. We can say that the ambient temperature at night has a big effect on the loss coefficient.

Comparison with two other systems of solar water heaters: The obtained results are compared with those of two other systems (ICS-2A with symmetrical CPC and ICS-2 with asymmetrical CPC) (Chaouachi and Gabsi, 2006). These two systems were tested in better material and weather conditions. With this aim, we compared the evolution of the mean daily efficiency according to the ratio of our system. The mean daily efficiency of each system (respectively ICS-2A and ICS-2) was calculated by the following formulas (Chaouachi and Gabsi, 2006):

$$
\begin{aligned}
& \eta_{\mathrm{ICS}-2 \mathrm{~A}}=0.689-4.138\left(\frac{\Delta \mathrm{T}}{\mathrm{G}_{\mathrm{m}}}\right)-6.831\left(\frac{\Delta \mathrm{T}}{\mathrm{G}_{\mathrm{m}}}\right)^{2} \\
& \eta_{\mathrm{ICS}-2}=0.50-3.46\left(\frac{\Delta \mathrm{T}}{\mathrm{G}_{\mathrm{m}}}\right)-10.11\left(\frac{\Delta \mathrm{T}}{\mathrm{G}_{\mathrm{m}}}\right)^{2}
\end{aligned}
$$

We notice from Fig. 9 and 10 that for both Southeastern and Southern orientations, the mean daily efficiency of our solar water heater prototype decreases quickly than those of the other systems. This is due on one hand to convecting thermal losses that are more important in our system and on the other hand to the fact that the performances of our solar water heater are evaluated for one day while the performances of the other ICS were evaluated for three days without water drain. In addition, for the Southwestern orientation given by Fig. 11, the mean daily efficiency of our system decreases more slowly than those of the systems ICS-2A and ICS-2. This can be explained by the fact that in our region the wind is dominant in from the Southern orientation, therefore its convecting effect on the glazing is reduced. Although thermal losses of our system are bigger than those of the other systems of studied ICS, its mean daily efficiency is comparable to the one of the system ICS-2.

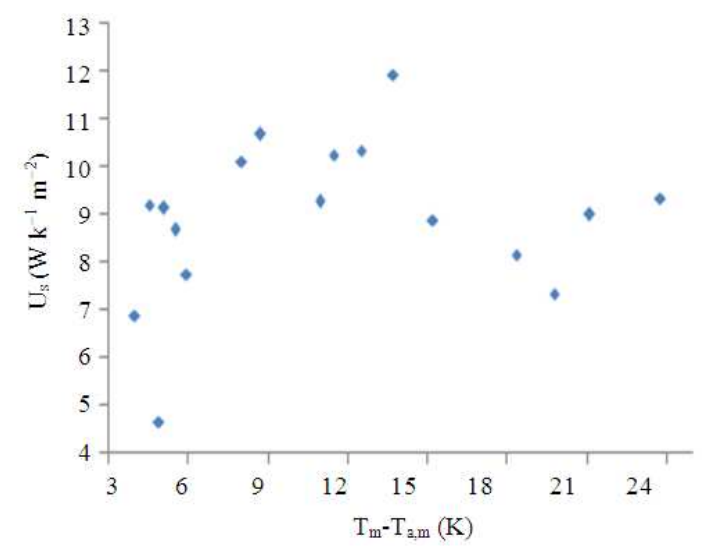

Fig. 8: Experimental results of the thermal losses coefficient during the night as function as $\left(\mathrm{T}_{\mathrm{m}}{ }^{-}\right.$ $\left.\mathrm{T}_{\mathrm{a}, \mathrm{m}}\right)$

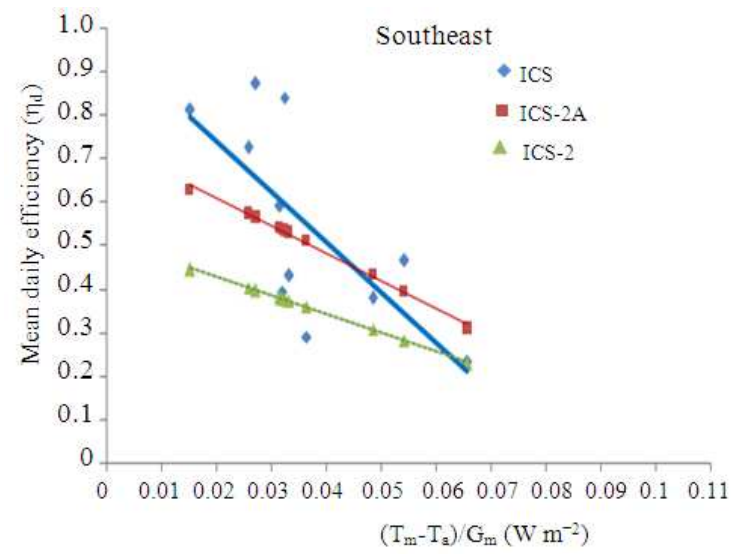

Fig. 9: Mean daily efficiency results for the different systems considered in the Southeastern orientation according to the ratio 
Am. J. Engg. \& Applied Sci., 3 (1): 152-158, 2010

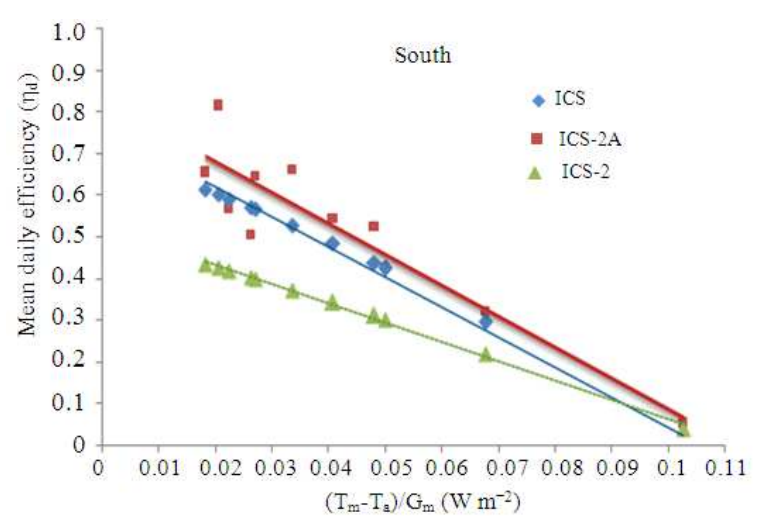

Fig. 10: Mean daily efficiency results for the different systems considered in the Southern orientation according to the ratio

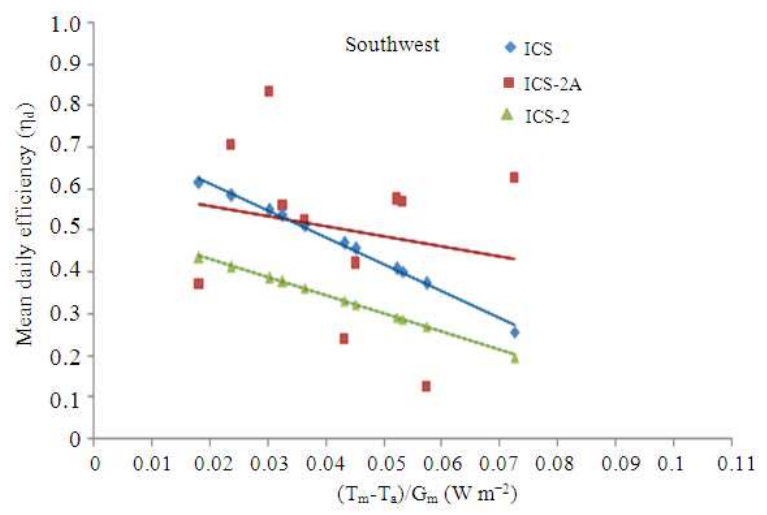

Fig. 11: Mean daily efficiency results for the different systems considered in the Southwestern orientation according to the ratio

\section{CONCLUSION}

The integrated collector storage solar water heater showed acceptable energetic performances and comparable to other solar water-heaters existing despite its simplicity and its little cost. In fact, according to the obtained results, we notice that the levels of water temperature of the storage tank are satisfactory and the production of hot water is sufficient for the user. Our system allows obtaining hot water from a mean temperature of $60^{\circ} \mathrm{C}$ and a ratio of 0,1 that is comparable to the obtained performances of the models introduced in the international market. Nevertheless, in order to commercialize this solar water heater, several improvements are necessary such as the evaluation of the position that increases the direct flow whilst decreases the thermal losses and therefore makes our system simpler to be installed on the building roof.
A detailed study on thermal losses due to the convecting radiating exchanges from the inferior and lateral surfaces and the glazing could help us to the improve our system.

\section{REFERENCES}

Adsten, M., A. Helegesson and B. Karlsson, 2005. Evaluation of CPC-collector designs for standalone, roof-or wall installation. Solar Energy, 79: 638-647. DOI: 10.1016/j.solener.2005.04.023

Chaouachi, B. and S. Gabsi, 2006. Etude expérimentale d'un chauffe-eau solaire à stockage intégré dans des conditions réelles. Rev. Energy Renew., 9: 75-82. http://www.webreview.dz/article.php3?id_article $=817$

Schmidt, C. and A. Goetzberger, 1990. Single-tube integrated collector storage systems with transparent insulation and involutes reflector. Solar Energy, 45: 93-100. DOI: 10.1016/0038092X(90)90033-9

Smyth, M., P.C. Eames and B. Norton, 1999. A comparative performance rating for an integrated solar collector/storage vessel with inner sleeves to increase heat retention. Solar Energy, 66: 291-303. DOI: 10.1016/S0038-092X(99)00027-4

Smyth, M., P.C. Eames and B. Norton, 2001. Annual performance of heat retaining integrated collector /storage solar water heaters in a northern maritime climate. Solar Energy, 70: 391-401. DOI: 10.1016/S0038-092X(00)00161-4

Smyth, M., P.C. Eames and B. Norton, 2004. Technoeconomic appraisal of an integrated collector/storage solar water heater. Renew. Energy, 29: 1503-1514. DOI: 10.1016/j.renene.2003.10.009

Souliotis, M. and Y. Tripanagnostopoulos, 2004. Experimental study of CPC type ICS solar systems. Solar Energy, 76: 389-408. DOI: 10.1016/j.solener.2003.10.003

Souliotis, M., S. Kalogirou and Y. Tripanagnostopoulos, 2009. Modeling of an ICS solar water heater using artificial neural networks and TRNSYS. Renew. Energy, 34: 1333-1339. DOI: 10.1016/j.renene.2008.09.007

Teyeb, A., L. Dehmani, A. Ben Ezzine, C. Kerkeni and L. Kaabi, 2006. Etude des Performances d'un capteur stockeur cylindro-parabolique. Rev. Energy Renew., 9: 135-141. http://www.webreview.dz/article.php3?id_article $=870$

Tripanagnostopoulos, Y. and M. Souliotis, 2004. ICS solar systems with horizontal (E-W) and vertical $(\mathrm{N}-\mathrm{S})$ cylindrical water storage tank. Renew. Energy, 29: 73-96. DOI: 10.1016/S09601481(03)00144-7 
Tripanagnostopoulos, Y. and P. Yianoulis, 1992. Integrated collector/storage systems with suppressed thermal losses. Solar Energy, 48: 31-43. DOI: 10.1016/0038-092X(92)90174-9

Tripanagnostopoulos, Y., M. Souliotis and Th. Nousia, 2002. CPC type integrated collector storage systems. Solar Energy, 72: 327-350. DOI: 10.1016/S0038-092X(02)00005-1
Tripanagnostopoulos, Y., P. Yianoulis, S. Papaefthimiou and S. Zafeiratos, 2000. CPC solar collectors with flat bifacial absorbers. Solar Energy, 69: 191-203. DOI: 10.1016/S0038-092X(00)00061-X 